\title{
Four Chiral Centers in a One Pot Procedure. Analogues of Isosorbide
}

Julio G. Urones, Isidro S. Marcos, Narciso M. Garrido, P. Basabe, Sonia G. San Feliciano, Raquel Coca and David Díez* Dpto. de Química Orgánica, Universidad de Salamanca. Plaza de los Caídos 1-5, 37008 Salamanca, SPAIN.

Received 28 September 1998

Abstract: Synthesis of analogues of isosorbide in one pot from 1-hydroxymethyl-4-phenylsulfonylbutadienes has been achieved.

In the previous paper, we have described a simple way to obtain 1-sulfonyl-1,3-dienes with adequate functionalization. These compounds have been the object of numerous studies in the last years, above all as dienes or dienophiles. ${ }^{1}$ Furthermore, it should be noted that there are more examples with sulfoxides rather than sulfones due to the potential chirality that these substrates ${ }^{2}$ can possess.

In our case, having developed a very easy way to get 1-sulfonyl-1,3dienes with an allylic alcohol, we wanted to exploit this feature to produce chiral compounds by way of the Sharpless enantioselective epoxidation. ${ }^{3}$

In this way, we planned to develop a short synthesis of analogues of isosorbide 1. Amino derivatives of $\mathbf{1}$ are being used as chiral auxiliaries ${ }^{4}$ in asymmetric synthesis while the dinitro derivative $\mathbf{2}$ and the piperazine derivative $\mathbf{3}$ possess antianginal activity ${ }^{5}$. 1, has been used recently as the starting material for the synthesis of novel bicyclic dideoxynucleosides as potential antiviral agents $4^{6}$<smiles>OC1CO[C@@H]2[C@@H](O)CO[C@H]12</smiles>

1 isosorbide<smiles>[O-][N+]1(O)CO[C@H]2[C@@H]1OC[C@H]2N1CCNCC1</smiles>

3<smiles>O=[N+]([O-])O[C@H]1CO[C@@H]2[C@@H]([N+](=O)[O-])CO[C@@H]12</smiles>

2

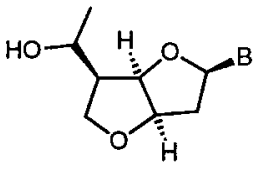

4
All different routes to isosorbide analogues start from isosorbide $\mathbf{1}$ as the starting material. In this context, we have found a new and versatile method to obtain analogues with different stereochemistry and functionalization, which allows not only the use of $\mathrm{SN}^{2}$ type reactions but also the use electrophilic reagents.

\section{Results and discussion}

Compound 6 was easily obtained as described in the previous paper by treatment of sulfone 5 with $n$-BuLi/THF at $-78^{\circ} \mathrm{C}$ (Scheme I).

Treatment of $\mathbf{6}$ with $n$-BuLi/THF followed by addition of acetone as the electrophile gives compound 7 in excellent yields (90\%). When 7 reacts with $m$-CPBA it afford compound 8 directly (77\%). The second cyclization proved to be difficult, with bases such as $\mathrm{NaH}$ or $\mathrm{KH}$ giving inconsistant results. However, use of Craig's conditions ${ }^{7}$ ( ${ }^{\mathrm{t}} \mathrm{BuOH} /$ ${ }^{\mathrm{t}} \mathrm{BuOK}$ 5:1) gave satisfactory yields of 9 (83\%).

When 7 reacts under Sharpless conditions with L-(+)-DET, after the usual work up of the reaction only homochiral (-)-98 is isolated. The stereochemistry was established by study of N.M.R. spectra and n.O.e. studies. The CIS relationship between H-4 and H-5 (mechanism) was confirmed by the n.O.e observed (Scheme I) and the same relationship of $\mathrm{H}-5$ and $\mathrm{H}-1$ was established for the existence of another n.O.e.

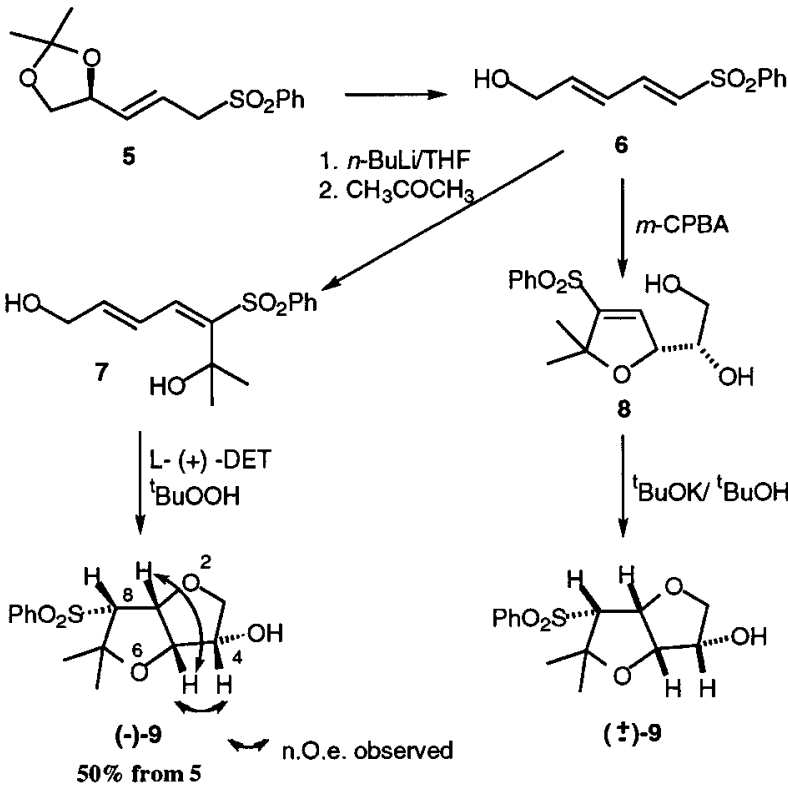

Scheme 1

between them. The stereochemistry of $\mathrm{H}-8$ was based on its coupling constant with $\mathrm{H}-1(\mathrm{~J}=5.8 \mathrm{~Hz})$, the other stereochemistry would give a nearly zero coupling constant, (see ref 4 ). This was confirmed by the existence of n.O.e between $\mathrm{H}-1$ and $\mathrm{H}-8$ in the bencil derivative.

So, in conclusion we have developed a short, and stereocontrolled way to obtain analogues of isosorbide. At the moment, we are trying to introduce further functionalization at $\mathrm{C}-8$, and a range of electrophiles are being used in the addition step.

Acknowledgement: This work was supported by Junta de Castilla y Leon (SA 44-96); M.E.C. and CICYT.

\section{References and Notes}

(1) a) Backwall, J.E.; Löfstrom, C.; Maffesal, M.; Lauger, V. Tetrahedron Lett. 1992, 33, 2417. b) Padwa, A.; Gareau, Y.; Harrison, B.; Norman, B.H. J. Org. Chem. 1991, 56, 2713.

(2) a) Aversa, M. C.; Baratucci, A.; Bonaccorsi, P.; Gianneto, P. Tetrahedron Asymm. 1997, 9, 1339. b) Carreño, M. C. Chem. Rev. 1995, 95, 1717.

(3) Gao, Y.; Hauson, R.M.; Klunder, J. M.; Ko, S. Y.; Masamune, H.; Sharpless, K. B. J. Am. Chem. Soc. 1987, 109, 5765

(4) Tamion, R.; Marsais, F.; Ribereau, P.; Queguiner, G.; Abenhaim, D.; Loupy, A.; Munnier, L. Tetrahedron Asymm. 1993, 8, 1879.

(5) Hayashi, H.; Keolo, J. I.; Kubo, K.; Mokiyama, J.; Karasama, A.; Suzuki, F. Chem. Pharm. Bull. 1993, 41, 1100

(6) Chao, Q.; Zhang, J.; Pickening, T. S.; Jahande, M.; Nair, V. Tetrahedron 1998, 54, 3113.

(7) a) Craig, D.; Ikin, M. J.; Mathews, N.; Smith, A. M. Tetrahedron Lett. 1995, 41, 7531. b) Padwa, A.; Gareau, Y.; Harrison, B.; Norman, B. H. J. Org. Chem. 1991, 56, 2713. 
(8) Spectral data for 9 :

(-)-9: $[\alpha]^{20}{ }_{D}=-39.9\left(\mathrm{c}=1.0, \mathrm{CHCl}_{3}\right)$; IR $\left(\mathrm{cm}^{-1}\right): 2930,2857,1719,1290$, 1152, 1084.; ${ }^{1} \mathrm{H}$ NMR $\left(400 \mathrm{MHz}, \mathrm{CDCl}_{3}\right): \delta 1.60(3 \mathrm{H}, \mathrm{s}, \underline{\mathrm{Me}}-\mathrm{C} 7), 1.61(3 \mathrm{H}, \mathrm{s}$, Me-C7), $3.29(1 \mathrm{H}, \mathrm{d}, \mathrm{J}=5.8 \mathrm{~Hz}, \mathrm{H}-8), 3.46\left(1 \mathrm{H}, \mathrm{dd}, \mathrm{J}=9.5\right.$ and $\left.6.6 \mathrm{~Hz}, \mathrm{H}_{\mathrm{B}}-3\right)$, $3.79\left(1 \mathrm{H}, \mathrm{dd}, \mathrm{J}=9.5\right.$ and $\left.5.5 \mathrm{~Hz}, \mathrm{H}_{\mathrm{A}}-3\right), 4.08(1 \mathrm{H}, \mathrm{m}, \mathrm{H}-4), 4.60(1 \mathrm{H}, \mathrm{t}, \mathrm{J}=5.8 \mathrm{~Hz}$,
H-5), $5.22(1 \mathrm{H}, \mathrm{t}, \mathrm{J}=5.8 \mathrm{~Hz}, \mathrm{H}-1), 7.60(2 \mathrm{H}, \mathrm{m}, \mathrm{Ar}), 7.66(1 \mathrm{H}, \mathrm{m}, \mathrm{Ar}), 7.91(2 \mathrm{H}$, m, Ar); ${ }^{13} \mathrm{C}$ NMR (100Mhz, $\mathrm{CDCl}_{3}$ ): $\delta 23.1$ (ㄹe-C7), 28.6 (Me-C7), 70.5 (C8), 71.9 (C-3), 76.6 (C-4), 78.3 (C-5), 85.0 (C-1), 86.8 (C-7), 128.2 (2CHortho, Ar), 129.2 (2CHmeta, Ar), 133.9 (CHpara, Ar), 134.0 (Cipso, Ar). Anal. Calcd for $\mathrm{C}_{14} \mathrm{H}_{18} \mathrm{O}_{5} \mathrm{~S}$ : C, 56.36; H, 6.08; Found: C, 56.35; H, 5.99. 